Viso - Cadernos de estética aplicada

Revista eletrônica de estética

ISSN 1981-4062

№ 5, jul-dez/2008

http://www.revistaviso.com.br/

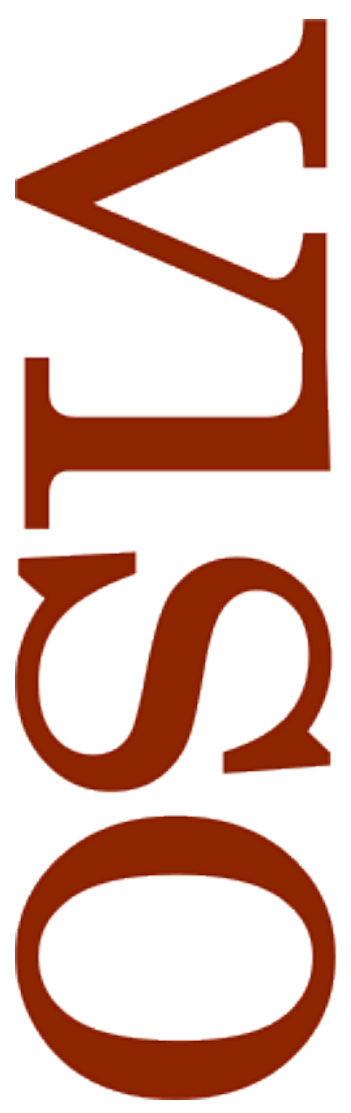

\title{
O olho torto de Alexandre: Ensaio sobre o alcance de uma visão maculada Tomás Prado
}




\section{RESUMO}

\section{O olho torto de Alexandre:}

\section{Ensaio sobre o alcance de uma visão maculada}

Notório personagem de Graciliano Ramos, Alexandre narra as aventuras da sua mocidade no nordeste rural. A primeira e principal delas trata do dia em que, por ocasião de ir buscar uma égua fugida, ele sofre um acidente no olho esquerdo que transforma a sua forma de ver o mundo. O universo fantástico de Alexandre coloca em suspenso as estruturas do real, oferecendo em seu lugar uma trama de aventuras da visão e da linguagem. Através de uma interpretação nietzschiana da narrativa, descobrimos como o olhar mobilizado - "solar" - vê melhor que o refalsadamente contemplativo, distante como a lua. Todo olhar é sempre comprometido. O mistério e a aventura estão no seu alcance.

Palavras-chave: literatura - Graciliano Ramos - Nietzsche

\section{ABSTRACT}

\section{Alexandre's squint eye:}

\section{Essay about the reach of a tarnished vision}

Striking character of Graciliano Ramos, Alexandre narrates the adventures of his youth in the rural northeast. The first and main one deals with the day on which, when trying to capture an escaped mare, he suffers an accident in the left eye that transforms the way he sees the world. The fantastic world of Alexandre challenges the structures of reality, offering in its place a web of adventures of vision and language. Through a Nietzschean interpretation of this narrative, we discover how the eye called - "sun" - sees better than the one which is contemplative, distant as the moon. Every look is always compromised. Mystery and adventure are within his reach.

Keywords: literature - Graciliano Ramos - Nietzsche 


\section{PRADO, T. "O olho torto de Alexandre: Ensaio sobre o alcance de uma visão maculada". In: Viso: Cadernos de estética aplicada, v. II, n. 5 (jul-dez/2008), pp. 80-90.}

DOI: $10.22409 / 1981-4062 / v 5 i / 67$

Aprovado: 19.11.2008. Publicado: 29.12.2008.

(C) 2008 Tomás Prado. Esse documento é distribuído nos termos da licença Creative Commons Atribuição-NãoComercial 4.0 Internacional (CC-BY-NC), que permite, exceto para fins comerciais, copiar e redistribuir o material em qualquer formato ou meio, bem como remixá-lo, transformá-lo ou criar a partir dele, desde que seja dado o devido crédito e indicada a licença sob a qual ele foi originalmente publicado.

Licença: http://creativecommons.org/licenses/by-nc/4.0/deed.pt_BR

Accepted: 19.11.2008. Published: 29.12.2008.

(C) 2008 Tomás Prado. This document is distributed under the terms of a Creative Commons Attribution-NonCommercial 4.0 International license (CC-BY-NC) which allows, except for commercial purposes, to copy and redistribute the material in any medium or format and to remix, transform, and build upon the material, provided the original work is properly cited and states its license.

License: http://creativecommons.org/licenses/by-nc/4.0/ 
'O que eu prefiro', assim ilude a si mesmo o iludido, 'seria amar a terra tal como a ama a lua, e acariciar sua beleza somente com os olhos'.

$[\ldots]$ Inocência e desejo de criar é todo o amor solar. Friedrich Nietzsche ${ }^{1}$

Entre os grandes clássicos do repertório nacional, Graciliano Ramos se destaca pelo extraordinário domínio da Língua Portuguesa, mas, em sua obra, notória é também a elaboração de temas universais. Dentro das cercas da fazenda São Bernardo, encontramos a alma russa, e, através do kafkiano olhar da cachorra "Baleia" - que expõe o universo fantástico, desconhecido para a maior parte dos modernistas brasileiros -, o drama seco da vida dos retirantes. Através da composição de inúmeros artifícios com uma cena específica, o cotidiano de brasileiros comuns, o autor promove um universo único em nossa literatura. O mesmo é possível afirmar sobre Alexandre e outros heróis obra de formato cômico, e talvez por isso circunscrita aos estudos escolares, mas que, a despeito dessa peculiaridade, será foco de interesse dos mais graves.

Nas primeiras páginas, as palavras do autor se antecipam à narrativa para apontar-nos sua fonte: "As histórias de Alexandre não são originais: pertencem ao folclore do Nordeste, e é possível que algumas tenham sido escritas". ${ }^{2}$ Pois bem, guardemos conosco esta homenagem à sabedoria popular nordestina e atenhamo-nos agora aos diferenciais da sua genialidade que têm a nos oferecer, um pouco distantes da bibliografia acadêmica, tão fecundas provocações.

Sem mais rodeios, apontamos as características mais marcantes de Alexandre. Como todo bom proseador de histórias da própria mocidade, usufrui o ócio, ou, na expressão roseana, à qual diversas vezes se assemelha em estilo, está "de range rede". ${ }^{3}$ Para tratar de todos os pormenores, apóia-se sempre em sua mulher, Cesária, seja para encontrá-los ou confirmá-los. Com Cesária, em momento nenhum e a respeito de coisa alguma Alexandre vem a discordar. Mas isso não é o mais importante. O que mais vale notar é que Alexandre "tinha um olho torto e falava cuspindo a gente" ${ }^{4}$ - marcas, certamente, do seu entusiasmo. Podemos entrever nesses dois detalhes o que é necessário para ser um grande contador de histórias: não ter o olho certo e deixar dançar a língua.

Como ocorre também em Vidas secas, Graciliano Ramos organiza a história dividindo-a em pequenos contos inteiramente auto-suficientes, mas que, remetendo-se um ao outro, formam um só linhol. A primeira historieta que Alexandre anuncia aos seus compadres deveria tratar das razões que lhe deixaram torto esse olho - tema ao qual em breve voltaremos. Entretanto, para a surpresa dos presentes, o caso desvia-se ao dia em que foi buscar no pasto uma égua fugida. 
Estava Alexandre "no copiar, esgaravatando a unha com a faca de ponta", quando seu pai vem Ihe indagar sobre o paradeiro da égua. Replicando que de nada sabia, seu pai então ordena que "dê umas voltas por aí" a ver se a encontra. "Nhor sim" - responde Alexandre, partindo em sua busca.

Entretido, esqueci o almoço e à tardinha descansei no bebedouro, vendo o gado enterrar os pés na lama. Apareceram bois, cavalos e miunça, mas da égua pampa nem sinal. Anoiteceu, um pedaço de lua branqueou os xiquexiques e os mandacarus, e eu me estirei na ribanceira do rio, de papo para o ar, olhando o céu, fui-me amadornando devagarinho, peguei no sono, com o pensamento em Cesária. ${ }^{6}$

No copiar, esgaravatando, entretido, amadornando, Alexandre se deixa estar. Vai à procura da égua de papo para o ar, com o pensamento longe em Cesária, e a tarde agradável passa até o sono, no encalço, alcançá-lo. Podemos cogitar: tudo isso é um só longo sono? Deixar-se levar pela ordem do pai será mesmo uma forma de se mobilizar? Ora, até aqui, que venha ou não a égua, tudo é um ótimo ensejo para a deliciosa modorra do dia. Da distração, entretanto, virá a transfiguração de tudo. Começa a aventura.

Alexandre desperta sob "uma escuridão medonha" e sente-se inseguro. Até confessa aos seus ouvintes: "Tive desejo de voltar para casa, mas o corpo morrinhento não me ajudou". ${ }^{7}$ De repente, "firmando a vista", percebe o vulto da desaparecida criatura abaixo, bebendo água no córrego. Cogitando, e preocupado com a história que contaria ao pai, decide o mais destrambelhado recurso.

Passei o cabresto no focinho da bicha e, os calcanhares presos nos vazios, deitei-me, grudei-me com ela, mas antes levei muita pancada de galho e muito arranhão de espinho rasga beiço. Fui cair numa touceira cheia de espetos, um deles esfolou-me a cara, e nem senti a ferida: num aperto tão grande não ia ocupar-me com semelhante ninharia. Botei-me para fora dali, a custo, bem maltratado. Não sabia a natureza do estrago mas pareceu-me que deveria estar com a roupa em tiras e o rosto lanhado. ${ }^{8}$

Depois do sono e do medo, mas pelo intento de agradar ao pai, Alexandre reúne coragem em demasia. Nesta passagem, conhecemos o que ocorrera com seu olho gauche, sinistro. Como, no entanto, o próprio Alexandre, preocupado com a captura da égua, neste passo dos fatos não se apercebera da conseqüência, a estória ainda segue em desvio. Luta "com puxavantes de cabresto, murros na cabeça e pancadas nos queixos" e, depois de subjugá-la, já com a bicha resignada dentro do cercado da fazenda e sob o espanto de todos os familiares, Alexandre enfim abrange a aventura em que inocentemente se enveredou:

- Tive medo, vi que tinha feito uma doidice. Vossemecês adivinham o que estava amarrado no mourão? Uma onça pintada, enorme, da altura de um cavalo. Foi por causa das pintas brancas que eu, no escuro, tomei aquela desgraçada pela égua pampa. ${ }^{10}$ 
A história anunciada do seu olho torto, e que parecia ter se perdido num caso paralelo, começa, portanto, por um prévio engano da visão. Precisamente por não ter discernido a égua da onça, Alexandre se acidentara no caminho. O sono despertou o medo, que firmou coragem. O que poderia ser tomado como um desvio da história anunciada tem como função, todavia, mostrar que a deformidade da sua visão não incidiu por acaso. Ela ocorreu, na verdade, precisamente porque lhe faltara a visão da clareza e lhe sobrara a visão da fantasia. Há em Alexandre inocência e desejo ainda não confrontados com o perigo. Desta visão que não percebe os riscos e considera o que quer nascerá uma sensibilidade extraordinária. Antes, contudo, é preciso perder-se e atravessar o perigo para que o bem de sua inocência e desejo não seja apenas ingênua ignorância e possa ainda tornar-se, na expressão de Nietzsche, uma experiência solar.

À semelhança do Quixote, que nasce já armado e montado no rocim, à cata de aventuras e deixando para trás todo Quijana, Quixana ou Quezada, nascer significa, aqui, cumprir um destino. Dom Quixote surge através da perspectiva do cavalheiro andante - perspectiva essa que não se cumpre estacionado. É preciso ver, também neste caso, o nascimento de uma perspectiva, a saber: Alexandre, o contador de fabulosas estórias. Afinal, esta primeira estória, que justifica o olho torto, é também a história das condições de e do contador. É preciso conhecer o modo como o menino surpreendido pela própria falta se torna autor.

$\mathrm{Na}$ parte seguinte da narrativa, depois do episódio da onça, Alexandre desfia mais profundo as venturas da sua vista. O propósito de contar o seu "defeito" se revela, então, ser apenas pretexto para demonstrar por que "o olho atravessado é melhor do que o outro"11 - e, aliás, do que todos os outros. Mas não nos adiantemos. Tratemos de compreender como o próprio Alexandre viu o que lhe faltava.

Uma desgraça, meus amigos, nem queiram saber. Antes de me espiar no vidro, tive uma surpresa: notei que só distinguia metade das pessoas e das coisas. Era extraordinário. Minha mãe estava diante de mim, e, por mais que me esforçasse, eu não conseguia ver todo o corpo dela. Meu irmão me aparecia com um braço e uma perna, e o espelho que me entregou estava partido pelo meio, era um pedaço de espelho. "Que trapalhada será esta?", disse comigo. E nada de atinar com a explicação. Quando me vi no caco de vidro é que percebi o negócio. Estava com o focinho em miséria: arranhado, lanhado, cortado, e o pior é que o olho esquerdo tinha levado sumiço. A princípio não assuntei o tamanho do desastre, porque só avistava uma banda do rosto. Mas virando o espelho, via o outro lado, enquanto o primeiro se sumia. ${ }^{12}$

Enquanto andara focado na tarefa de domar a besta, Alexandre de nada apercebera da sua condição - não fora capaz de ver que não via. Toda a sua entrega recaía sobre o olho da vontade, o olho esforçado em dominar o ente selvagem. Quando, porém, apontam o que the falta, o olho soberano da vontade empaca, vacila. É como se o sono, já transmutado em medo e coragem, tornasse a se insinuar. Como se lhe dissesse: não vale a pena ter coragem; quiete o facho. O que, assim, ocupa o espaço cedido é a dúvida, o faltoso. Alexandre, em conseqüência, realiza que não vê, ou ainda, que vê tudo em parte - estipulando que seja a exata metade. Durante o arrebatamento da luta, a 
sensibilidade (sensibilis - estar voltado para direções e estímulos diversos) ficara pelo caminho em favor do ímpeto. Agora, ao dar-se cômputo do perigo que correra, e preocupado com sua integridade, alcança o que deveria ter notado. $\mathrm{O}$ que ele, enfim, repara é que segue sem ver o que em tudo Ihe escapara. Há algo que falta. Há algo que falta nas pessoas e que no espelho não encontra em si mesmo. É certo que essa falta causará angústia, mas quem sabe não poderá também abrir, com renovada coragem, novos horizontes? Tudo tem sua hora.

Ao experimentar o engano, Alexandre se torna carente de objetividade. O pertencimento à luta dera lugar, dizemos mais uma vez em referência a Nietzsche, à ilusão de poder amar a terra tal como faz a lua, distante e refalsadamente contemplativa. A decepção com a acuidade da sua visada fere a suposta capacidade de sujeitar os obstáculos e, coberto de vergonha das suas potências, Alexandre parece contentar-se agora com a segurança contemplativa das formas ideais. Nos terrenos em que transita, nada permanece o que é esperado, tudo pode surpreender, e é nesse espaço da possível transformação abrupta que ele enxerga o vazio.

O trauma do engano e a insegurança pela possibilidade do erro maltratam-Ihe o orgulho. Alexandre agora pisa de leve, sorrateiramente, demasiado cauteloso, como um gato, à procura do "puro conhecimento", que, entretanto, aponta-lhe apenas a falta. Este é o tema do canto de Zaratustra, denominado "Do imaculado conhecimento". Nietzsche trata de melindrosos e lascivos que, por terem perdido a inocência do desejo, passam a caluniá-lo.

Embora busque objetividade, falta-lhe, contudo, reserva para entrever nas coisas o que são - o sentido ontológico que sustenta todo aparecer numa possibilidade de eclosão (a ser, mais do que contrariada, protegida). Digamos: falta reconhecer a diferença ontológica de Heidegger? Perdoe o silêncio em favor de outro apego de estilo, e talvez um excesso de licença ensaística.

Falta-lhe, quem sabe, entre o sono e a sanha, outra tonalidade afetiva, uma... simpatia (?!). Ao saber que a vontade não apenas não pode dar, mas faz-lhe perder a clareza, Alexandre se prostra, amuado, como se alguém tivesse lhe pregado uma peça, como se tivesse sido iludido. Mas se não pela vontade, se não montando nos entes e acertandoIhes murros no queixo, como haverá de abarcá-los? Será, acaso, com rezas? Responde: "Não havia curandeiro nem rezador que me endireitasse, pois mezinha e reza servem pouco a uma criatura sem olho, não é verdade, seu Gaudêncio?". ${ }^{13}$

É certo que reza alguma poderá restituir a figura integral das coisas e a sua própria figura. Difícil é assegurar o que - se o olho ou a coisa -, compromete primeiro o que. Ao que parece, de tanto investigar avessos, ambos estão, na verdade, mutuamente comprometidos, e é isso o que aos poucos Alexandre notará. Mas não apressemos o passo. 
Alexandre encontra-se inseguro e busca a solidão. Sem resignar-se, entretanto, acaba encontrando uma modesta esperança, que vem a ser: a possibilidade de refazer o caminho em que se perdera e, ali, reencontrar o olho que, acredita, não trará de volta a visão, mas ao menos, tapando "aquele buraco vermelho", restituiria a sua "boa figura". ${ }^{14}$ Nessa parte, Alexandre infere que, embora condenado a ver de modo precário as pessoas e todo o resto, pior é que elas o vejam em estado precário, ou seja, que vejam o que nele é faltoso. É, portanto, preenchendo aos olhos dos outros a sua própria figura, que ele a esse ponto espera restituir a sua integridade. É preocupado com o seu daimon - apenas acessível aos outros -, que ele espera restituir a sua eudaimonia (bem-estar). Lembremos de como o coro se refere a Édipo: "A desgraça dos mortais é serem cegos ao próprio daimon". ${ }^{15}$

Deixemos o pobre Édipo em paz, em favor de um caso diverso de cegueira.

\begin{abstract}
Já estava desanimando quando o infeliz me bateu na cara de supetão, murcho, seco, espetado na ponta de um carrancho todo coberto de moscas. Peguei nele com muito cuidado, limpei-o na manga da camisa para tirar a poeira, depois encaixei-o no buraco vazio e ensangüentado. E foi um espanto, meus amigos, ainda hoje me arrepio. Querem saber o que aconteceu? Vi a cabeça por dentro, vi os miolos, e nos miolos muito brancos as figuras de pessoas em que eu pensava naquele momento. Sim senhores, vi meu pai, minha mãe, meu irmão tenente, os negros, tudo miudinho, do tamanho de caroços de milho. É verdade. Baixando a vista, percebi o coração, as tripas, o bofe, nem sei que mais. Assombrei-me. Estaria malucando? Enquanto enxergava o interior do corpo, via também o que estava fora, as catingueiras, os mandacarus, o céu e a moita de espinhos, mas tudo isso aparecia cortado, como já expliquei: havia apenas uma parte das plantas, do céu, do coração, das tripas, das figuras que se mexiam na minha cabeça. Refletindo, consegui adivinhar a razão daquele milagre: o olho havia sido colocado pelo avesso. ${ }^{16}$
\end{abstract}

É mais uma vez de modo abrupto, "de supetão", distante do fito antecipatório e domesticador da vontade (agora ferida), que surge para Alexandre um novo sentido. $\mathrm{O}$ olho que, digamos, é o da sensibilidade aguçada - o próprio páthos ${ }^{17}$, que se deixa arrebatar, mas que se perde no caminho (levando a face de tudo) - de súbito captura-o, "bate-lhe na cara", ensina-Ihe uma boa lição; enfim, encontra a si mesmo. Se antes caíra em digressão, recobra-se, agora, literalmente, introvertendo. Já estava empoeirado e às moscas - maculado - mas, de modo inesperado, o olho pega, porque é remetido a uma direção ou estímulo diferente. "Encaixado no buraco", Alexandre vê "a cabeça por dentro, os miolos, e nos miolos muito brancos as figuras de pessoas em que pensava naquele momento". Alexandre aprende, quiçá, um meta-olhar, mas este é ainda bambo (como todo conceito ou interpretação de conteúdo inconsciente); permanece contra-senso, que Ihe faz até especular estar "malucando". Enquanto vê o interior do corpo, e aprende com a experiência como a imagem de tudo está gravada nas vísceras, vê também o que está fora, mas tudo, de dentro e de fora, estando disperso, segue faltante, com uma metade subtraída. 
Aos poucos as experiências da visão se tornam para Alexandre mais complexas. Em lugar da vontade desenfreada e de uma objetividade segura, Alexandre recorre à procedência; realiza uma genealogia. Esse percurso demonstra como o alcance e a acuidade requerem não a dissecação de perspectivas, mas a sua implicação. A falta que notava nas coisas de dentro e de fora, por fim, deu lugar a uma análise do modo de se posicionar, em suma, não da sua psiqué - que não foi o que encontrara dentro da cachola -, mas da sua morada [éthos]: ser-em. Se antes perdera a visão por atacar a esmo o que desconhecia, em seguida perde por evitar implicar-se. Tanto a aproximação de punhos cerrados quanto o distanciamento da desilusão não foram capazes de oferecer a figura integral das coisas. Apenas um dar-se conta da implicação entre a própria falta e a falta das coisas, como que se combinando uma à outra, poderia perfazer o que lhe fosse possível alcançar, restituindo um contorno nas coisas, uma perspectiva ${ }^{18}$ - que fosse também o seu próprio.

O que o olho perdido vem ao encontro apontar é a desmedida. Se o que antes faltava era a sensibilidade, o que agora falta é, mais uma vez nas palavras de Zaratustra:

Ousai, primeiro, acreditar em vós mesmos - e nas vossas vísceras! Quem não acredita em si mesmo mente sempre. ${ }^{19}$

Mas é preciso reparar: acreditar em si mesmo não significa julgar-se competente para esbofetear e submeter tudo ao redor. Acreditar em si mesmo, com inocência e desejo, significa implicar-se.

Afinal, refletindo sobre uma e outra, dentro e fora, coração, memória, pensamento, espinhos e céu, o avesso pôde, não supomos que endireitar-se, mas como que em tudo adivinhar e atravessar um sentido e uma imagem - posto que, para ver, e isto bem sabe todo bom contador de histórias, também é preciso preencher lacunas.

Meti o dedo no buraco do rosto, virei o olho e tudo se tornou direito, sim senhores. Aqueles troços do interior se sumiram, mas o mundo verdadeiro ficou mais perfeito que antigamente. Quando me vi no espelho, depois, é que notei que o olho estava torto. Valia a pena consertá-lo? Não valia, foi o que eu disse comigo. Para que bulir no que está quieto? E acreditem vossemecês que este olho atravessado é melhor que o outro. ${ }^{20}$

A possibilidade de compor e encontrar uma integridade nas coisas, como foi dito, passa pelo posicionamento ou implicação. É preciso reconhecer que somos sempre já lançados entre as coisas, e que elas não são frutos de nossas raízes transcendentais, mas, antes, dos caminhos e veredas em que lutamos - nos perdendo e nos encontrando. Há um copertencimento que às vezes demonstra como as raízes estão distantes do nosso controle, e é mais que tudo nesse momento que o alcance é a questão. Por isso, afirmamos que reconhecer a implicação (o éthos - a nossa morada ou condição ontológica), é necessário, mas não resolve ainda a questão do alcance (ôntico). É, digamos, apenas uma condição necessária para não se perder nos fragmentos e não se iludir em soberbas de autonomia. O alcance é a forma própria de preencher e 
harmonizar o que falta aqui com o que excede ali, e vice-versa, na medida em que uma dada imersão causa arrebate. Todo arrebate é um encontrão e, por isso, não pode ser orientado por pai nenhum. Quando, acreditando em si mesmo, Alexandre lança-se novamente numa busca, ele inicia não apenas a sua história, mas a sua autoria (no olhar). E assim, depois de velho, Alexandre avalia o que, no trabalho conjunto dos olhares, cabe a cada um; e valora até onde cada um, por mérito, habilidade e, sobretudo por capacidade de $\operatorname{amar}^{21}$, é capaz de atingir.

Inocência e desejo de criar é todo o amor solar..$^{22}$

Há um olho que é melhor que o outro. O olho que ficou em seu lugar, à semelhança da lua, que "acaricia a beleza da terra somente com os olhos", quando domou feras foi ingênuo e, desiludido, tornou-se vacilante. $\mathrm{O}$ outro - que se perdera e encontrara o inesperado, que fora maculado, mas alcançou o desconhecido, o extraordinário - agora quieto enxerga mais longe, com o modo solar de proceder. Alexandre, então, conhece o que é revelado pela inocência e pelo desejo criador: o mundo verdadeiro é o que pode ficar mais perfeito, ainda que por resultado de um olho atravessado.

\section{* Tomás Prado é doutorando em filosofia pela PUC/RJ.}

${ }^{1}$ NIETZSCHE, F. "Do imaculado conhecimento" In: Assim falou Zaratustra. São Paulo: Círculo do Livro, 1990, p. 136.

${ }^{2}$ RAMOS, G. Alexandre e outras histórias. Rio de Janeiro: Record, 2005.

${ }^{3}$ GUIMARÃES ROSA, J. Grande Sertão: Veredas. Rio de Janeiro: Nova Fronteira, 2001, p. 26.

${ }^{4}$ RAMOS, G. Op. cit., p. 11.

${ }^{5}$ Ibidem, p. 16.

${ }^{6}$ Ibidem, p. 17.

${ }^{7}$ Ibidem, p. 17.

${ }^{8}$ Ibidem, pp. 18-19.

${ }^{9}$ Ibidem, p. 19.

${ }^{10}$ Ibidem, p. 20

${ }^{11}$ Ibidem, p. 26.

${ }^{12}$ Ibidem, p. 24

${ }^{13}$ Ibidem, p. 24.

${ }^{14}$ Ibidem, p. 25

${ }^{15}$ SÓFOCLES apud ARENDT, H. A condição humana. Rio de Janeiro: Forense Universitária, 2008, pp. 205-206.

${ }^{16}$ RAMOS, G. Op. Cit., p. 25 
${ }^{17}$ HEIDEGGER, M. "Que é isto - a filosofia?" In: Os pensadores. São Paulo: Editora Abril Cultural, 1979, p. 215: "Páthos remonta a páskhein, sofrer, agüentar, suportar, tolerar, deixar-se levar por, deixar-se convocar por".

${ }^{18}$ ORTEGA Y GASSET, J. Meditaciones del Quijote. Madrid: Cátedra, 1998, p. 71: "Cuándo nos abriremos a la convicción de que el ser definitivo del mundo no es materia ni es alma, no es cosa alguna determinada - sino una perspectiva?".

${ }^{19}$ NIETZSCHE, F. Op. cit., p. 136.

${ }^{20}$ RAMOS, G. Op. cit., p. 26.

${ }^{21}$ ORTEGA Y GASSET, J. Op. cit., p. 104: "Desconocer que cada cosa tiene su propia condición y no la que nosotros queremos exigirle es, a mi juicio, el verdadero pecado capital, que yo llamo pecado cordial por tomar su oriundez de la falta de amor. Nada hay tan ilícito como empequeñecer el mundo por medio de nuestras manías y cegueras, disminuir la realidad, suprimir imaginariamente pedazos de lo que es".

${ }^{22}$ NIETZSCHE, F. Op. cit., p. 136. 